\title{
Shear capacities for hybrid steel beams jacketed within reinforced concrete ends connected to reinforced concrete columns
}

\author{
K. Kanemoto \\ Institute of Technology, Shimizu Corporation, Japan
}

\begin{abstract}
This paper discusses the structural performance of hybrid steel beams jacketed with reinforced concrete at ends connected to a reinforced concrete $(\mathrm{R} / \mathrm{C})$ column. In order to figure out the shear transfer mechanism at the hybrid beam ends, tested under shear loads were the specimens of a half scale with changing the amount of shear reinforcement at the hybrid beam ends, with different types of construction method such as precast, and with different anchoring details of the steel edge end to the columns. Based on the experimental data, the author proposes the shear capacity estimation for the hybrid steel beam ends embedded in $\mathrm{R} / \mathrm{C}$ beam.

Keywords: hybrid structure, beam, reversed cyclic loading, stress transfer mechanism, ultimate shear strength.
\end{abstract}

\section{Introduction}

This paper describes an overview of the test program on hybrid structural steel beams, jacketed with reinforced concrete at the ends. In response to a drastic increase in construction material prices, hybrid structures - both R/C and steel have been further developed.

Conventional hybrid structures, composed of $\mathrm{R} / \mathrm{C}$ columns and steel beams, are constructed in complex ways due to the steel beams passing through the columns with cover plates at the joint, so insufficient concrete can be poured in because of the column rebars set at each corners. Under the circumstances, the author developed a hybrid steel beam jacketed with reinforced concrete at ends connected to reinforced concrete columns as one of the solutions [1,2], leading to long spanned frame structures. 
Although such structures have been developed [3-6] in the past, as shown in Reference [6] the ultimate shear strength of the $\mathrm{R} / \mathrm{C}$ jacketed might be overestimated as long as the bearing stress acting between the embedded structural steel and the $\mathrm{R} / \mathrm{C}$ jacket is assumed to be distributed linearly. Based on the test results, the author proposed an appropriate estimation for the ultimate shear strength of $\mathrm{R} / \mathrm{C}$ jackets.

\section{Overview and features of hybrid structure}

Figure 1 shows the overview of the hybrid structure. This is the hybrid joints system beams, often used for rigid frames of hybrid structures consisting of $\mathrm{R} / \mathrm{C}$ columns and steel beams. Steel beams with a consequent span of neighboring columns face-to-face, jacketed with $\mathrm{R} / \mathrm{C}$ at the ends, are connected to the columns. This system makes it possible to realize the rigid frame structures with the stress transfer mechanism between the steel beam and the $\mathrm{R} / \mathrm{C}$ jacket at the ends.

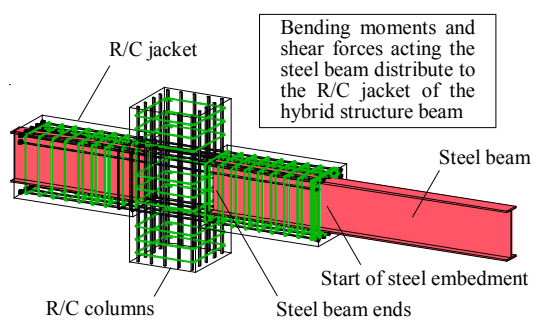

Figure 1: Overview of hybrid structure.

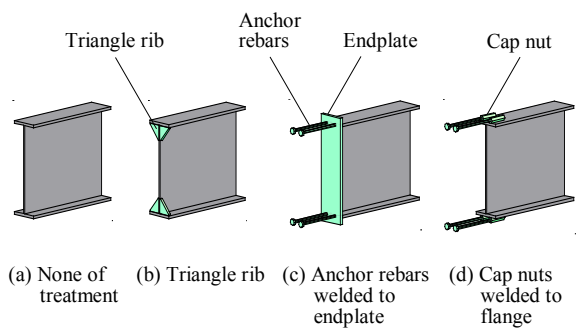

Figure 2: Details of steel beam ends.

As for details of steel beam ends, as shown in Fig. 2, there are several types of such ends with no stiffeners and with triangle ribs or anchor rebars. These stiffeners are expected to control the resistant moment at the ends.

The features of the hybrid structures are summarized as follows:

1. Steel beam ends are jacketed with reinforced concrete. This makes the beam more rigid, compared to steel structures, loading to a more rigid frame as a whole. Since the steel beams become rigid, less vertical deflection and less interstory drift are expected in the structures.

2. Smaller sizes in the jacket steel sections are expected than in ordinary steel structures or conventional hybrid ones.

3. As long as plastic hinges are designed to be formed at critical sections of the steel beam, the frame structures show more ductile and energy-dissipating behaviors than $\mathrm{R} / \mathrm{C}$ jackets do. In order to realize the preferable situation, local buckling of the steel flange or shear buckling of webs should be avoided. 
4. Since the structural steel does not cross the R/C column at the joint, the column's rebars can be easily set at the joint.

5. Details of structural steel ends are very simple (as shown in Fig. 2).

6. Precast concrete $(\mathrm{PCa})$ jackets including beam-column joints are available, because the joints are made of $\mathrm{R} / \mathrm{C}$.

\section{Overview of test programs}

\subsection{Specimen}

Table 1 shows a list of the specimens. Specimen configuration, the size, and details of reinforcement are shown in Fig. 3. Figure 4 indicates the typical beam sections at A-A' in Fig. 3 for specimens No.1-1 and No.4-1, as well as representative specimens No.5-1 and No.5-2. A total number of seven specimens, about half-scaled models, have fourteen parameters such as the construction method of column and beam (site cast or PCa construction), triangle ribs or anchor rebars at steel ends, concrete strength, and failure modes of hybrid beams.

Table 1: $\quad$ List of specimens.

\begin{tabular}{|c|c|c|c|c|c|c|c|c|c|}
\hline \multirow{2}{*}{ Specimens } & \multirow{2}{*}{$\begin{array}{c}\text { Steel beam size } \\
(\mathrm{mm})\end{array}$} & \multicolumn{3}{|c|}{$\mathrm{R} / \mathrm{C}$ jacket size $(\mathrm{mm})$} & \multirow{2}{*}{$\begin{array}{c}\text { Longitudinal } \\
\text { rebars }\end{array}$} & \multirow{2}{*}{ Stirrups } & \multirow{2}{*}{$\begin{array}{l}\text { Concentrated } \\
\text { stirrups }\end{array}$} & \multirow{2}{*}{$\begin{array}{c}\text { Types of steel } \\
\text { end detail } \\
\text { (See Fig. 2) }\end{array}$} & \multirow{2}{*}{ Remarks } \\
\hline & & Width/ & Height & Length & & & & & \\
\hline No.1-1 & $\mathrm{H}-400 \times 125$ & \multirow{2}{*}{430} & \multirow{2}{*}{630} & \multirow{2}{*}{850} & \multirow{2}{*}{ 7-D22 } & \multirow{2}{*}{ 4-S6@60 } & \multirow{2}{*}{3 set of 4-S6@6 } & (b) & \multirow{2}{*}{$* 1$} \\
\hline No.1-2 & $\times 8 \times 13$ & & & & & & & (a) & \\
\hline No.2-1 & H- $400 \times 125$ & \multirow{2}{*}{340} & \multirow{2}{*}{630} & \multirow{2}{*}{850} & \multirow{2}{*}{ 7-D22 } & \multirow{2}{*}{ 4-S6@100 } & \multirow{2}{*}{3 set of 4-S6@30 } & (a) & $* 2$ \\
\hline No.2-2 & $\times 8 \times 13$ & & & & & & & (a) & $* 1$ \\
\hline No.3-1 & $\mathrm{H}-400 \times 150$ & \multirow{2}{*}{430} & \multirow{2}{*}{580} & \multirow{2}{*}{850} & \multirow{2}{*}{ 7-D22 } & \multirow{2}{*}{ 4-S6@50 } & \multirow{2}{*}{3 set of 4-S6@6 } & (b) & \multirow{2}{*}{ *1 } \\
\hline No.3-2 & $\times 8 \times 13$ & & & & & & & (a) & \\
\hline No.4-1 & $\mathrm{H}-400 \times 150$ & \multirow{2}{*}{340} & \multirow{2}{*}{580} & \multirow{2}{*}{850} & \multirow{2}{*}{ 7-D22 } & \multirow{2}{*}{ 4-S6@100 } & \multirow{2}{*}{3 set of 4-S6@30 } & (a) & $* 3$ \\
\hline No.4-2 & $\times 8 \times 13$ & & & & & & & (a) & $* 1$ \\
\hline No.5-1 & $\mathrm{H}-400 \times 150$ & \multirow{2}{*}{340} & \multirow{2}{*}{580} & 580 & $4-\mathrm{D} 22$ & 4 46@100 & 3 set of $4-\mathrm{S} 6 \Omega 30$ & (c) & *2 \\
\hline No.5-2 & $\times 8 \times 13$ & & & 580 & $4-D \angle 2$ & 4-S6@100 & 3 set or 4-sb@30 & (d) & 2 \\
\hline No.6-1 & $\mathrm{H}-400 \times 150$ & 430 & 630 & 850 & $6-D 19$ & 4-S6@100 & 3 set of 4-S6@6 & (a) & $* 1$ \\
\hline No.6-2 & $\times 8 \times 13$ & 400 & 630 & 850 & 6-D19 & 2-S6@120 & 3 set of 2-S6@6 & (a) & +1 \\
\hline No.7-1 & $\mathrm{H}-400 \times 150$ & 400 & 630 & 850 & 6-D19 & 2-S6@140 & 3 set of 2-S6@6 & (a) & $* 1$ \\
\hline No.7-2 & $\times 8 \times 13$ & 400 & 050 & 850 & 6-D19 & 2-S6@160 & 3 set or 2-so@o & & \\
\hline
\end{tabular}

*1: Site cast beam end and column *2: PCa beam end, and site cast column *3: Site cast beam end, and PCa column
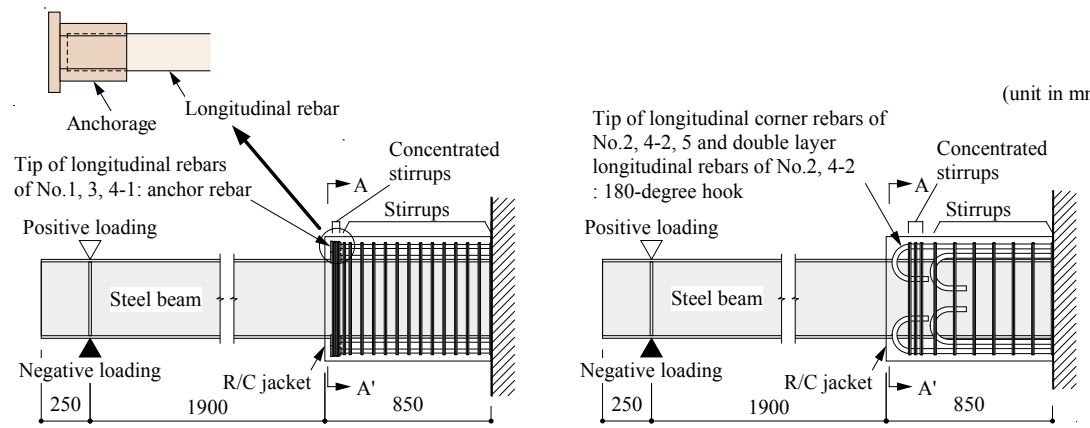

Figure 3: $\quad$ Specimen's configuration and details of reinforcement. 


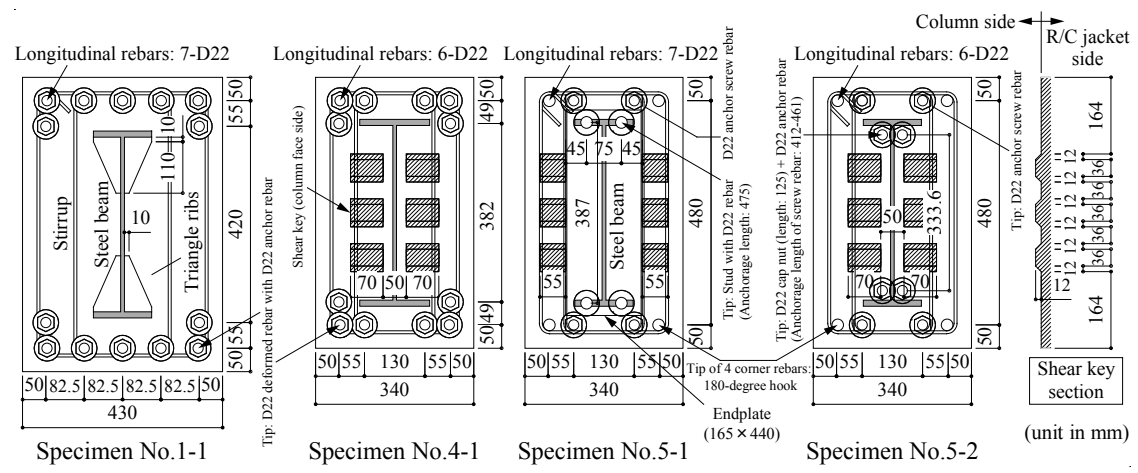

Figure 4: $\quad$ Typical cross sections of $\mathrm{R} / \mathrm{C}$ jacket.

The triangle ribs in specimens No.1-1 and No.3-1 are fillet welded along the ends contacting to the H-shaped steel. In specimen No.5-1 the end plate is welded to the end of the steel in $\mathrm{R} / \mathrm{C}$ jacket, specifically full penetration welded with V-shaped grooves and gouging for flanges, and filet welded for web. In specimen No.5-2 the cap nuts are filet welded to the flange of H-shaped steel ends. A series of specimen No.4 (No.4-1 and No.4-2) is fabricated firstly with a site cast column and beam for specimen No.4-2, and secondly with a site cast beam on the other side afterwards for specimen No.4-1. Consequently, this column can be regarded as a PCa column for No.4-1. Concrete is placed vertically in the same manner as in the actual construction.

Table 2 shows the mechanical properties of materials used for the specimens. The compression test and static modulus test of elasticity for concrete comply

Table 2: $\quad$ Mechanical properties of materials.

(a) Concrete

\begin{tabular}{cccc}
\hline Specimens & $\begin{array}{c}\text { Compressive } \\
\text { strength } \\
(\mathrm{MPa})\end{array}$ & $\begin{array}{c}\text { Splitting tensile } \\
\text { strength } \\
(\mathrm{MPa})\end{array}$ & $\begin{array}{c}\text { Young's } \\
\text { modulus } \\
\left(\times 10^{4} \mathrm{MPa}\right)\end{array}$ \\
\hline No.1-1 & 35.3 & 2.98 & 29.9 \\
\hline No.1-2 & & 2.59 & 30.2 \\
\hline No.2-1 & 33.0 & 2.90 & 30.4 \\
\hline No.2-2 & 31.1 & 2.57 & 28.9 \\
\hline No.3-1 & 33.9 & 2.9 & 30.4 \\
No.3-2 & & 2.59 & 30.2 \\
\hline No.4-1 & 31.1 & 2.59 & 30.2 \\
No.4-2 & 33.0 & 3.59 & 36.7 \\
\hline No.5-1 & 33.0 & 4.67 & 38.7 \\
\hline No.5-2 & No.6-1 & 75.3 & \\
No.6-2 & & & \\
\hline No.7-1 & 75.5 & 4.67 \\
No.7-2 & & & \\
\hline
\end{tabular}

(b) Reinforcement and steel

\begin{tabular}{|c|c|c|c|c|}
\hline Parts & & $\begin{array}{c}\text { Yield } \\
\text { strength } \\
(\mathrm{MPa}) \\
\end{array}$ & $\begin{array}{c}\text { Young's } \\
\text { modulus } \\
\left(\times 10^{5} \mathrm{MPa}\right)\end{array}$ & Remarks \\
\hline \multirow{3}{*}{$\begin{array}{l}\text { Longitudinal } \\
\text { rebar }\end{array}$} & \multirow{2}{*}{ D22 } & 437 & 189 & No. 2,4 \\
\hline & & 441 & 190 & No. 1,3 \\
\hline & D19 & 428 & 187 & No. 6,7 \\
\hline \multirow{3}{*}{ Stirrup } & \multirow{3}{*}{ D6 } & $988^{*}$ & 183 & No. $2,4,5$ \\
\hline & & $1025^{*}$ & 183 & No. 1,3 \\
\hline & & $986^{*}$ & 183 & No.6, 7 \\
\hline \multirow{2}{*}{ Anchor rebar } & \multirow{2}{*}{ D22 } & 364 & 194 & No.5-1 \\
\hline & & 437 & 189 & No.5-2 \\
\hline \multirow{8}{*}{ Steel beam } & \multirow{4}{*}{ Flange } & 351 & 200 & No. $2,4,5$ \\
\hline & & 348 & 186 & No. 1,3 \\
\hline & & 355 & 202 & No.6 \\
\hline & & 358 & 210 & No.7 \\
\hline & \multirow{4}{*}{ Web } & 413 & 195 & No. $2,4,5$ \\
\hline & & 414 & 196 & No. 1,3 \\
\hline & & 423 & 200 & No.6 \\
\hline & & 426 & 201 & No.7 \\
\hline Endplate & PL-19 & 373 & 202 & No.5-1 \\
\hline Triangle rib & PL-9 & 362 & 184 & No.1-1,3-1 \\
\hline
\end{tabular}


with the "JIS A1108 Method of tests for compressive strength of concrete" and "JIS A 1149 Method of test for static modulus of elasticity of concrete". Splitting tensile tests were conducted in a manner complying with the "JIS A 1113 Method of concrete splitting tensile strength test". Steel tensile test pieces are fabricated in compliance with "JIS Z 2201 Test pieces for tensile test for metallic materials" The tensile test was conducted as specified in "JIS Z 2241 Methods for tensile test for metallic materials". Concrete used for the tests are Fc24, Fc30 and Fc60 (Fc refers to the nominal strength). Other materials used for the tests include deformed bars D19 and D22 for longitudinal rebar, and D6 for stirrup (the numbers refer to the nominal diameter). For structural steel, a flange of $\mathrm{H}$ $400 \times 200 \times 8 \times 13$ is cut into a width $(125 \mathrm{~mm}$ or $150 \mathrm{~mm})$ as specified.

All specimens have the same condition for shear span in beams, depths of steel beams and the $\mathrm{R} / \mathrm{C}$ jacket (length: $850 \mathrm{~mm}$ ). The anchor rebars for specimen No.5-1 are the deformed D22 rebars welded to the endplate of the steel beam. As for specimen No.5-2 the anchor rebars are screwed into the cap nuts welded to the inside of the top and bottom flanges.

\subsection{Loading configuration}

Figure 5 shows the loading configuration. The axial load was applied to the column so as to be more than the total load of shear loads in both beams due to yield moment. In order to prevent steel beams from lateral buckling at the larger deformation, out-of-plane bracings are placed under the beam. The $1000 \mathrm{kN}$ compression and tension hydraulic jack at each end of both steel beams is used for applying the load as shear. Both left and right beams are independently controlled by the beam deformation angle $R(R$ : the ratio of vertical displacement $\left(\delta_{v}\right)$ in the beam divided by steel beam length $(L)$ (see Fig. 6).

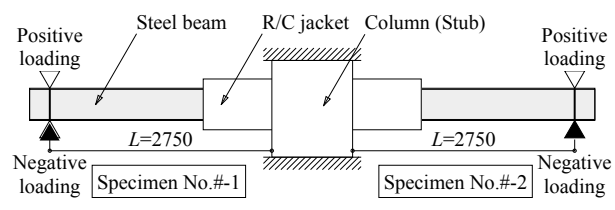

Figure 5: Loading configuration.

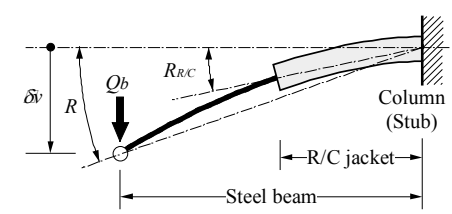

Figure 6:
Definition of deformation angle.

The loading cycles are repeated twice at $R= \pm 0.25, \pm 0.5, \pm 1.5 \% \mathrm{rad}$., and three times at $R= \pm 1.0, \pm 2.0 \% \mathrm{rad}$., followed by a cycle of $R= \pm 3.0 \% \mathrm{rad}$, and then up to $R=+5.0 \%$ rad. For specimens No.6 and No.7, however, the loading cycles at $R= \pm 1.0$ and $\pm 2.0 \%$ rad. are repeated three times.

\subsection{Test results}

\subsubsection{Characteristics of failure}

Figure 7 shows the relationships between shear load vs. deformation angle for each specimen. All specimens experienced flexural cracks at the critical section 
of the $\mathrm{R} / \mathrm{C}$ jackets at $R= \pm 0.25 \% \mathrm{rad}$, and then flexural shear cracks in the $\mathrm{R} / \mathrm{C}$ jackets at $R= \pm 0.5 \% \mathrm{rad}$, and shear cracks at $R= \pm 1.0 \% \mathrm{rad}$.
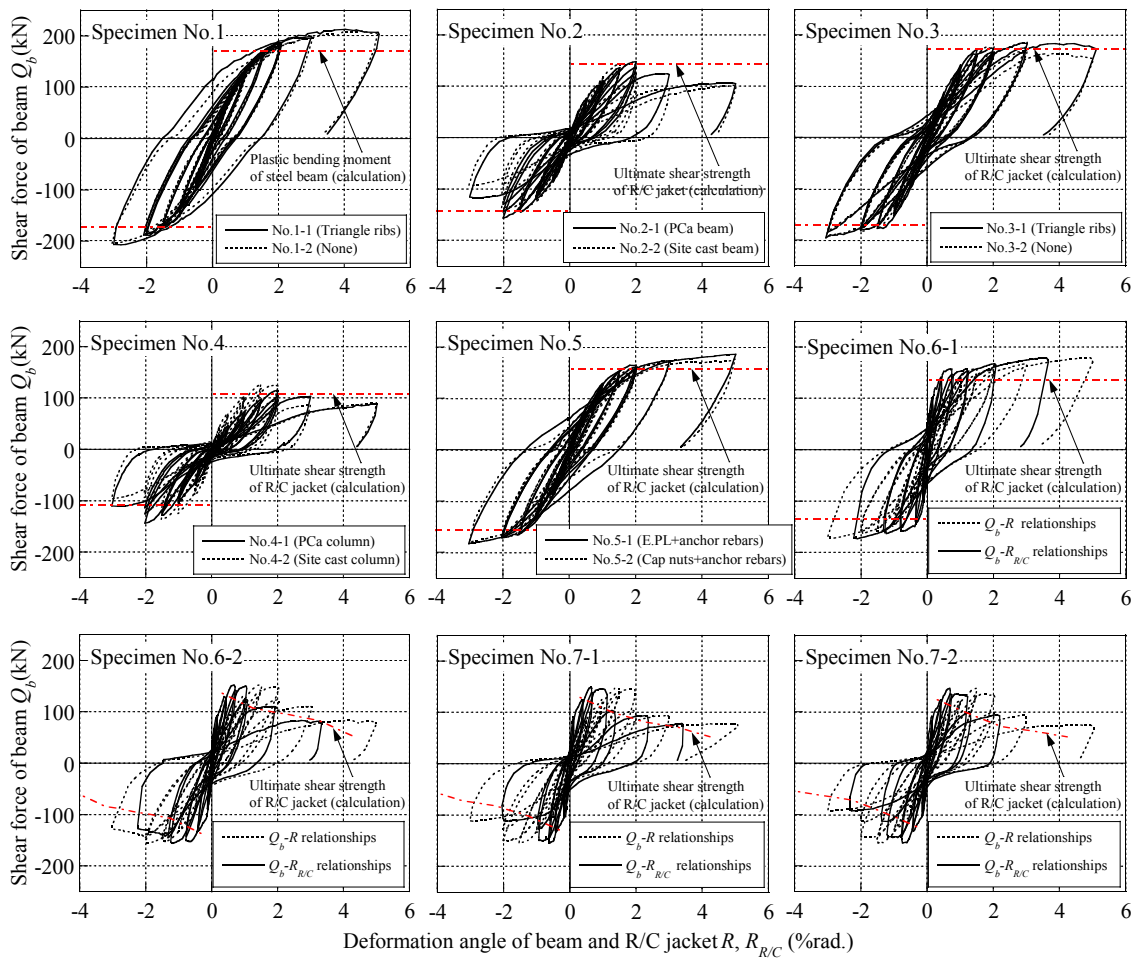

Figure 7: $\quad$ Deformation angle of beam and $\mathrm{R} / \mathrm{C}$ jacket $R, R_{R / C}$.

Specimen No.1: cracks observed at the R/C jacket for specimen No.1-1 with the triangle ribs at the end of steels being, on the whole, smaller than those for specimen No.1-2 without the triangle rib. Both specimens No.1-1 and No.1-2 in the meantime experienced yielding of the flange at the start of the steel embedment at $R=+1.0 \%$ rad. For specimen No.1-2, concrete was fractured at the concentrated stirrups at the $\mathrm{R} / \mathrm{C}$ jacket at $R=+5.0 \%$ rad. Both specimens showed the spindle-shaped relationship between the load vs. deformation, which means that these specimens are sufficiently capable of absorbing energy as long as yielding is expected at the flange of the steel. Even up to $R=+5.0 \% \mathrm{rad}$., the load remained stable.

Specimen No.2: once the specimen reached the ultimate strength at $R=+2.0 \%$ rad., a shear failure occurred at the $\mathrm{R} / \mathrm{C}$ jacket with decreasing loads, shear cracks at the $\mathrm{R} / \mathrm{C}$ jacket at $R= \pm 2.0 \% \mathrm{rad}$. were larger for specimen No.2-2 with a site cast column and beam than those for specimen No.2-1 with a PCa beam. Both specimens No.2-1 and No.2-2 showed a shear failure beyond 
$R=+2.0 \%$ rad. No significant decrease in strength was found for PCa construction after the ultimate strength was reached, unlike behavior observed in the specimen with site cast construction.

Specimen No.3: these specimens showed the flexural yielding of rebars in $\mathrm{R} / \mathrm{C}$ jackets. Even up to $R=+5.0 \% \mathrm{rad}$, the load remained stable. The cracks at the $\mathrm{R} / \mathrm{C}$ jacket were smaller for specimen No.3-1 with the triangle ribs at the steel ends than those for specimen No.3-2 without the triangle rib. Both specimens No.3-1 and No.3-2 showed the yielding of the beam longitudinal rebar at $R=+1.5 \% \mathrm{rad}$.

Specimen No.4: once the ultimate strength was reached at $R=+2.0 \%$ rad., a shear failure occurred at the $\mathrm{R} / \mathrm{C}$ jacket with decreasing loads. Until the maximum load was reached, the load for site cast construction remained higher than that for a $\mathrm{PCa}$ construction. The cracks at the $\mathrm{R} / \mathrm{C}$ jacket were larger for specimen No. 4-2 with the site cast column and beam than those for specimen No.4- 1 with a PCa construction up to $R=+5.0 \%$ rad. Both specimens No.4- 1 and No.4-2 showed a shear failure beyond $R=+2.0 \%$ rad., and for specimen No.4-2 the $\mathrm{R} / \mathrm{C}$ jacket was significantly deformed.

Specimen No.5: both specimens No.5-1 and No.5-2 showed the yielding of the beam longitudinal rebar at $R=+2.0 \% \mathrm{rad}$. These specimens showed the flexural yielding of rebars in $\mathrm{R} / \mathrm{C}$ jackets. The test results showed no reduction in strength even at $R=+5.0 \% \mathrm{rad}$. Regardless of the specification of the anchor rebars, no significant difference in structural behaviors was found between the two specimens. The cracks in the $\mathrm{R} / \mathrm{C}$ jacket were relatively smaller than those for other specimens.

Specimen No.6: the beam longitudinal rebar in the $\mathrm{R} / \mathrm{C}$ jacket showed the yielding at $R=+1.0 \% \mathrm{rad}$. For specimen No.6-1, the load kept increasing up to the final cycle of testing, showing stable behaviors. Specimen No.6-2 showed a significant decrease in strength and eventual shear failure after $R= \pm 2.0 \% \mathrm{rad}$. was reached, followed by the beam longitudinal rebar's yielding at $R=+1.0 \% \mathrm{rad}$.

Specimen No.7: specimen No.7 with less shear reinforcement compared to specimen No.6, the beam longitudinal rebars yielded at $R=+1.2 \% \mathrm{rad}$. A significant decrease in strength was found after $R=+2.0 \% \mathrm{rad}$., as in the case of specimen No.6-2.

\subsubsection{Shear force distribution of steel beam in $\mathrm{R} / \mathrm{C}$ jacket}

Figure 8 shows the strain measurement locations for steel webs. Figure 9 shows the shear force coefficients (defined as the ratio of the shear in steel beam divided by the beam shear forces) at $R=+1.0 \% \mathrm{rad}$., $1.5 \% \mathrm{rad}$., $2.0 \% \mathrm{rad}$. respectively for specimens No.1-2 and No.2-2 as examples. The shear force in steel beams was calculated by the integral of shear stress with respect to steel depth. The shear stress was given by the three-axis wire strain gauges from the three locations in a section of the steel web. The shear stress at a section with only one set of three-axis wire strain gauges was calculated based on the assumption that the shear stress distribution be proportional to the one at the section with three sets of the three-axis wire strain gauges. 


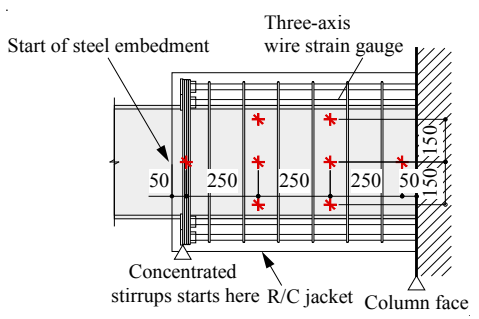

Figure 8: $\quad$ Measurement of locations of strain in steel web.
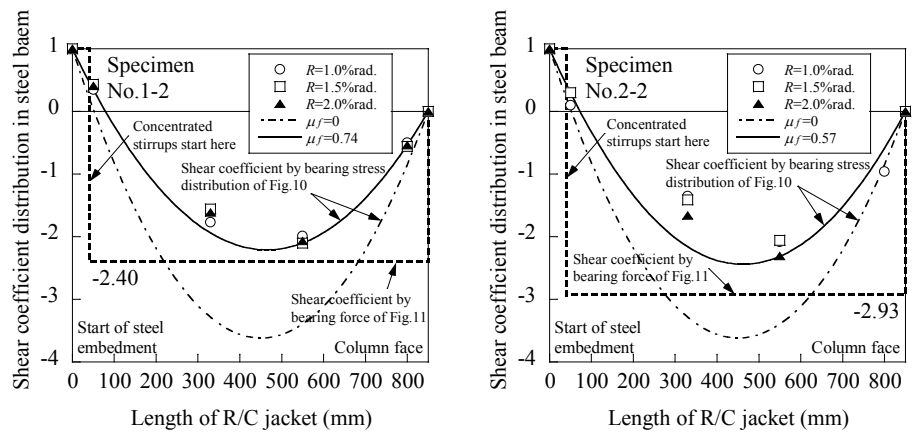

Figure 9: Shear coefficient distribution in steel beam.

The single dotted line in Fig. 9 shows the shear force coefficient distribution of the steel beams given by the calculation not considering frictions due to a bearing pressure (friction coefficient $=0$ ). On the other hand, assuming a triangle distribution of the bearing force and stress distribution between steel flanges and concrete in the $\mathrm{R} / \mathrm{C}$ jacket as shown in Fig. 10, the shear force coefficient distribution of the steel beam can be represented by the solid line. Estimating the friction coefficients so as to be fitted with the experimental shear force coefficients, the coefficients could be taken as 0.74 and 0.57 for specimens No.12 and No.1-2 respectively. The dashed line in Fig. 9 represents the shear force coefficient distribution of steel beams, based on the calculation assuming that two concentrated loads act on the steel beam in opposite ways from the column face and the concentrated stirrups as shown in Fig. 11. The shear force distribution of the steel beams, with concentrated loads given, shows a line enveloping the shear force distribution considering frictions due to bearing forces. This indicates that the structure can be regarded to be safe even if the bearing force and stress distribution are estimated by the two concentrated loads. 


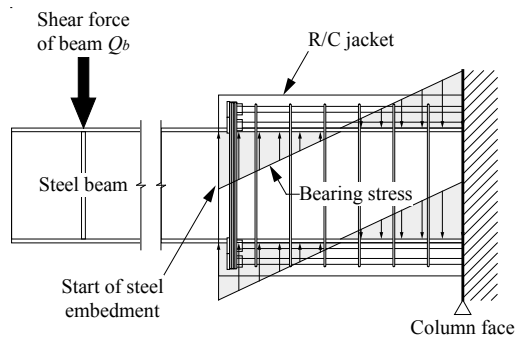

Figure 10: Bearing stress distribution acting on steel beam.

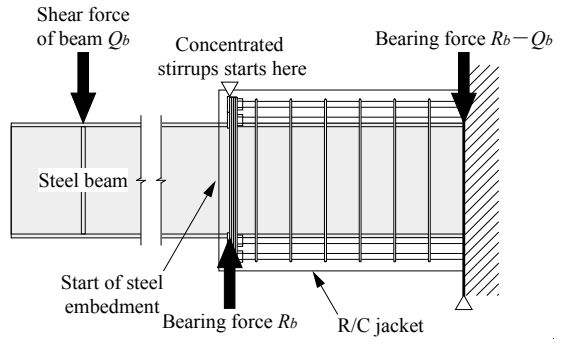

Figure 11: Concentrated bearing force acting on steel beam.

\section{Evaluation of strength}

\subsection{Evaluation equation for ultimate flexural and shear strength}

The ultimate flexural strength at the critical section in the $\mathrm{R} / \mathrm{C}$ jacket was consistent with that described in Reference [7]. The fully plastic moment of the steel section is evaluated in accordance with Reference [8]. If anchor rebars or triangle ribs are installed at the end of steels, the shear force acting on the $\mathrm{R} / \mathrm{C}$ jacket may be mitigated, because the bending moment could be partly covered by those elements.

The ultimate flexural strength for that case is evaluated with an equation incorporating the ultimate flexural strength of beam longitudinal rebars and the plastic flexural strength of steels, in which the resistant moment due to the bearing force of triangle ribs is added as well. The resistant moment given by the bearing force of triangle ribs is shown in eqn. (1). In order to properly apply the resistant moment, however, the plate should be sufficiently thick to prevent the triangle ribs from yielding.

$$
\begin{gathered}
M_{s}=C_{s} \cdot{ }_{s} j \\
C_{s}=\beta \cdot \sigma_{B} \cdot A_{s}, \quad A_{s}=\frac{\left(b_{s}-{ }_{w} t\right)^{2}}{4}, \quad{ }_{s} j={ }_{w} d-\frac{b_{s}-{ }_{w} t}{3}
\end{gathered}
$$


where,

$C_{s}$ : Total of bearing forces acting on triangle ribs

$\beta$ : Assuming 0.6 as an effective coefficient of the bearing force and stress of the concrete (calculated using the friction coefficient in Section 3.3.2)

$\sigma_{B}$ : Compressive strength of concrete

$s^{j}$ : Distance between the centroids of the top and bottom triangle ribs

${ }_{w} t$ : Steel web thickness

$b_{s}:$ Steel flange width

${ }_{w} d$ : Steel web length

Reaction forces to the steel beam, as discussed in Section 3.3.2, are to be taken as two concentrated loads. With regards to the $\mathrm{R} / \mathrm{C}$ jacket section, the reaction force is considered to act as a shear force through bearing forces and frictions acting between the steel flange and concrete in accordance with flexural deformation of the beam increasing. The authors decided to evaluate the ultimate shear strength of the R/C jacket section with eqn. (2) as referring to the strength calculation of Reference [9]. Assuming the truss and arch systems in the R/C jacket section, for the effective width of $\mathrm{R} / \mathrm{C}$ section the steel flange width is to be subtracted from the $\mathrm{R} / \mathrm{C}$ jacket section width.

$$
\begin{gathered}
{ }_{r} Q_{u}=\min \left({ }_{r} Q_{u 1},{ }_{r} Q_{u 2},{ }_{r} Q_{u 3}\right) \\
{ }_{r} Q_{u 1}=\mu \cdot p_{w e}^{\prime} \cdot \sigma_{w y} \cdot b_{e}^{\prime}+\left[v \cdot \sigma_{B}-\frac{\left(1+\cot ^{2} \phi\right) p_{w e}^{\prime} \cdot \sigma_{w y}}{\lambda}\right] \frac{b^{\prime} \cdot D}{2} \tan \theta \\
{ }_{r} Q_{u 2}=\frac{\lambda \cdot v \cdot \sigma_{B}+p_{w e}^{\prime} \cdot \sigma_{w y}}{3} b_{e}^{\prime} \cdot j_{e} \\
{ }_{r} Q_{u 3}=\frac{\lambda \cdot v \cdot \sigma_{B}}{2} b_{e}^{\prime} \cdot j_{e} \\
\mu=\cot \phi\left(1-10 R_{p}^{\prime}\right), \quad \cot \phi=\min \left(2, L_{j e} / j_{e}\right), \quad R_{P}^{\prime}=R_{R / C}-R_{y}
\end{gathered}
$$

where,

${ }_{r} Q_{u} \quad$ : Ultimate shear strength of the end $\mathrm{R} / \mathrm{C}$ jacket section

${ }_{r} Q_{u 1}$ : Shear strength of the truss system due to stirrups

${ }_{r} Q_{u 2}:$ Shear strength of the truss system due to stirrups and concrete

${ }_{r} Q_{u 3}:$ Shear strength of the truss system due to concrete

$\mu \quad$ : Truss angle coefficient

$R_{p}^{\prime} \quad$ : Plastic deformation angle of $\mathrm{R} / \mathrm{C}$ jacket

$R_{R / C}:$ Deformation angle of $\mathrm{R} / \mathrm{C}$ jacket

$R_{y} \quad$ : Deformation angle when beam longitudinal rebar yields

$\cot \phi$ : Truss system angle

$b_{e}^{\prime} \quad$ : Effective width for $\mathrm{R} / \mathrm{C}$ jacket section in the truss system, which is considered to be as Fig. 12, depending on how the slabs are placed

$j_{e}$ : Distance between centroid toward the shear force in the direction of the outside stirrup 
$p_{\text {we }}$ : Effective stirrup ratio

$p^{\prime}{ }_{w e}={ }_{w} a_{s} / b_{e}^{\prime} \cdot s$, where, ${ }_{w} a_{s}: 1$ set of stirrup's sectional area,

$s$ : stirrup's pitch

$\sigma_{w y}:$ Stirrup's yield strength

$\lambda \quad$ : Effective coefficient of truss system

$v \quad$ : Effective coefficient of concrete compressive strength

${ }_{w} a$ : Sectional area of concentrated stirrups, ${ }_{w} a={ }_{s} Q_{u} / \sigma_{w y}$

${ }_{s} Q_{u}$ : Ultimate shear strength acting on the end of concentrated stirrups

\subsection{Evaluation results for ultimate flexural and shear strength}

The single dotted line in Fig. 7 represents to the ultimate strength calculation values. Table 3 shows comparisons of the experimental ultimate strength and the calculated values converted to shear force in the beam. Figure 7 also shows the cases for specimens No.1, No.3 and No.6-1, which are of flexural yielding represented by the line of calculated strength, and specimens No.2, No.4, No.6-2, No.7, which are of a type of shear failure represented by the line of the ultimate shear strength calculated as eqn. (2). The calculated strength lines for specimens No.1-5 represent the smaller value between the two specimens. The lines for specimens No. 2 and No.4 show the values at $R_{p}^{\prime}=0$.

The experimental ultimate shear strength is consistent with that calculated by eqn. (2) for specimens No. 2 and 4, with the R/C jacket. For specimen No.6-2, the beam longitudinal rebars yielded at $R=+1.0 \% \mathrm{rad} .\left(R_{R / C}=+0.5 \% \mathrm{rad}.\right)$, and the strength was decreased at/after $R=+2.0 \%$ rad. For specimen No.7, beam longitudinal rebars yielded at $R=+1.2 \%$ rad., as shown in specimen No.6-2, and then strength decreased after $R=+2.0 \% \mathrm{rad}$. The maximum shear force of beams for specimen No.1 corresponded with the calculated value of the plastic flexural strength of steels. For the flexural yield type specimens No.3, No.5 and No.6-1,

Table 3: $\quad$ Experimental and calculated maximum strength.

\begin{tabular}{|c|c|c|c|c|c|c|}
\hline \multirow[b]{2}{*}{ Specimens } & \multirow{2}{*}{$\begin{array}{l}\text { Maximum shear } \\
\text { force of beam } \\
\text { (Experiment) } \\
(\mathrm{kN})\end{array}$} & \multicolumn{3}{|c|}{ Ultimate shear force of beam (Calculation) $(\mathrm{kN})$} & \multirow[b]{2}{*}{$\frac{\text { Experiment }}{\text { Calculation }}$} & \multirow[b]{2}{*}{ Failure mode } \\
\hline & & $\begin{array}{l}\text { Bending yield } \\
\text { of } \mathrm{R} / \mathrm{C} \text { jacket }\end{array}$ & $\begin{array}{l}\text { Plastic bending } \\
\text { of steel beam }\end{array}$ & $\begin{array}{l}\text { Shear force of } \\
\text { R/C jacket }\end{array}$ & & \\
\hline No.1-1 & 211.6 & 229.5 & 171.3 & 359.2 & 1.24 & \multirow{2}{*}{ Yielding of steel flange } \\
\hline No.1-2 & 209.0 & 220.7 & 171.3 & 329.2 & 1.22 & \\
\hline No.2-1 & 148.3 & 219.3 & 172.8 & 150.1 & 0.99 & \multirow{2}{*}{ Shear failure of $\mathrm{R} / \mathrm{C}$ jacket ${ }^{* 1}$} \\
\hline No.2-2 & 145.7 & 219.3 & 172.8 & 144.0 & 1.01 & \\
\hline No.3-1 & 185.5 & 183.7 & 194.4 & 303.8 & 1.01 & \multirow{2}{*}{$\begin{array}{l}\text { Flexural yielding of } \\
\text { rebars in } \mathrm{R} / \mathrm{C} \text { jacket }{ }^{* 2}\end{array}$} \\
\hline No.3-2 & 186.5 & 171.5 & 194.4 & 262.5 & 1.09 & \\
\hline No.4-1 & 114.4 & 170.6 & 196.0 & 108.0 & 1.06 & \multirow{2}{*}{$* 1$} \\
\hline No.4-2 & 127.5 & 170.6 & 196.0 & 112.6 & 1.13 & \\
\hline No.5-1 & 186.8 & 157.0 & 196.0 & 324.4 & 1.19 & \multirow{2}{*}{$* 2$} \\
\hline No.5-2 & 177.7 & 158.4 & 196.0 & 330.3 & 1.12 & \\
\hline No.6-1 & 179.4 & 135.2 & 189.9 & 318.4 & 1.33 & $* 2$ \\
\hline No.6-2 & 152.0 & 135.2 & 189.9 & 170.7 & 1.12 & $* 3$ \\
\hline No.7-1 & 148.7 & 135.2 & 190.9 & 146.3 & 1.10 & \multirow{2}{*}{$\begin{array}{c}\text { Shear failure after flexural } \\
\text { yielding of rebars in } \mathrm{R} / \mathrm{C} \text { jacket }{ }^{* 3}\end{array}$} \\
\hline No.7-2 & 146.7 & 135.2 & 190.9 & 128.0 & 1.15 & \\
\hline
\end{tabular}



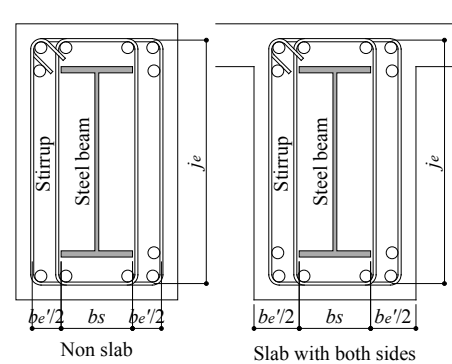

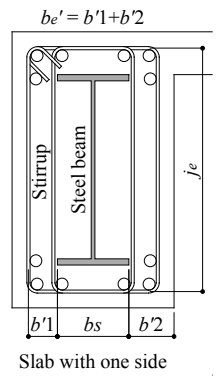

Figure 12: $\quad$ Effective width for $\mathrm{R} / \mathrm{C}$ jacket.

the experimental ultimate strength was reasonably consistent with the calculated ultimate flexural capacity for an R/C jacket. Since specimen No.5-1 has endplates at the steel ends, the ultimate flexural capacity value could be designed by considering a resistant moment due to the endplates, as in the case of the triangle rib. The authors, however, would not incorporate this effect in the evaluation for safer consideration. The ultimate strength was mostly estimated safe for all specimens. The failure mode for each specimen was also consistent with the test result. Thus, the ultimate strength by the evaluation proposed in this study turned out to be effective. The evaluation is based on the existing ultimate flexural strength calculations and the revised ultimate shear strength ones.

\section{Conclusions}

Specimens of about half a scale were tested to identify a structural performance of the hybrid structure of steel for the beam midspan and the $\mathrm{R} / \mathrm{C}$ jacketed beam ends, connecting to $\mathrm{R} / \mathrm{C}$ columns, and to investigate the stress transfer in steel and concrete in the $\mathrm{R} / \mathrm{C}$ jacket. Major findings obtained through the study based on the results of the test are summarized as follows:

1. No difference in structural behaviors due to the difference of construction methods of columns and beams (site cast or PCa construction) was found.

2. Anchor rebars at the steel ends are effective in partly covering the bending moments at the beam ends, thus the shear force in the $\mathrm{R} / \mathrm{C}$ jacket can be mitigated.

3. The ultimate flexural strength can be evaluated by the existing equations.

4. The shear span of the $\mathrm{R} / \mathrm{C}$ jacket, used to evaluate the ultimate shear strength, should be taken as the one measured from the column face to the start point of concentrated stirrups, in which the bearing and friction forces acting between steel flange and concrete are taken into account.

5. The ultimate shear strength in the $\mathrm{R} / \mathrm{C}$ jacket can be evaluated by the method proposed in this paper. 


\section{References}

[1] Kiyo-omi Kanemoto, Shinji Mase, Koji Yamanobe, An estimation of shear capacities for hybrid steel beams jacketed with reinforced concrete at ends connected to reinforced concrete column, Journal of Structural and Construction Engineering, Architectural Institute of Japan, Volume 76, No. 659, pp. 205-211, 2011 (in Japanese with English summary).

[2] Koji Yamanobe, Kiyo-omi Kanemoto, Shinji Mase, Structural performance of hybrid steel beams with the ends reinforced by concrete connected to R/C column, Part 5: Effects of high strength concrete and steel plate shear reinforcement, Summaries of Technical Papers of Annual Meeting Architectural Institute of Japan, pp. 1183-1184, 2009 (in Japanese).

[3] Kazuhiro Kanda, Seiji Yoshizaki, Naoshi Miyazaki, Hifumi Kawabata, Test of structural members in tall buildings utilizing the $\mathrm{R} / \mathrm{C}$ layered construction system, Part 8: Experimental study on combined beams consist of $\mathrm{R} / \mathrm{C}$ and steel member, Summaries of Technical Papers of Annual Meeting Architectural Institute of Japan, pp. 305-306, 1987 (in Japanese).

[4] Hiroyuki Narihara, Mitsuru Izumi et al. Experiment and strength calculation of combined beam consist of $\mathrm{R} / \mathrm{C}$ and steel member, Taisei Research Institute Technical Report, No. 26, 1993 (in Japanese with English summary).

[5] Yukio Hagiwara, Katsuhiko Yamaguchi et al. Development of composite beam consists of R/C and steel member, Asanuma Technical Research Report, No. 11, 1999 (in Japanese with English summary).

[6] Hideyuki Suzuki, Hiroshi Nishihara, Shear strength and deformation performance of hybrid beam consisting of H-shaped steel and reinforced concrete, Journal of Structural and Construction Engineering, Architectural Institute of Japan, Volume 73, No. 631, pp. 1673-1680, 2008 (in Japanese with English summary).

[7] Architectural Institute of Japan, Standard for Structural Calculation of Reinforced Concrete Structures - Based on Allowable Stress Concept, 2010 (in Japanese).

[8] Architectural Institute of Japan, Design Standard for Steel Structures Based on Allowable Stress Concept, 2005 (in Japanese).

[9] Architectural Institute of Japan, Design Guidelines for Earthquake Resistant Reinforced Concrete Buildings Based on Inelastic Displacement Concept, 1999 (in Japanese). 